\title{
River bed deformations near banks and hydraulic structures due to river flow
}

\author{
A. E. Schodro \\ Department of Hydraulic Engineering, \\ National University of Water and Natural Recourses Management, \\ Rivne, Ukraine
}

\begin{abstract}
Estimating local scouring associated with structures placed in rivers and streams, e.g. bridge piers, bridge abutments, spur dykes etc., is an important facet of their design. However, due to the non-uniformity of alluvial channel bed and bank materials and the complex nature of the fluid-sediment-structure interactions and sediment transport processes, the calculated maximum scour depth for a given flow condition is normally regarded as being approximate, at best. This study investigates the nature of local scouring formed by vortices that are generated behind partially submerged river bed features having slanted ridges, and behind the ridges of scour holes. Modified theoretical relations developed for local scouring are compared with the results of experiments performed in laboratory channels having both rigid and moveable (test-bed) sections. At selected intermediate stages of the bed-scouring process, maximum velocities and turbulence intensities were measured at the bottom of developing scour holes. Two mathematical models for forecasting rearrangement of the river bed in a zone of local deformations are used. One considers scouring in beds composed of relatively homogeneous small sand particles, while the other is appropriate for channel beds comprised of non-homogeneous materials.

Keywords: nonstationary local scour, concentrated scour, bridge piers, spur dyke, submerged river-bed installations, river-bed regulation scheme, mathematical modeling.
\end{abstract}




\section{Introduction}

It's well known that maximum local scouring of river channel beds occur shortly after the maximum discharge condition, i.e. as a flood is in the process of receding. Accordingly, from a 'scouring failure'-related viewpoint, the period immediately following the flood-peak should be regarded as being the most dangerous. The resulting formations of sediment bars at channel bend sections redirects flows towards river banks. Secondary flow phenomena initiated by the bar features result in intensifying of the scouring process. Regulating structures, such as spur-dykes, 'bendway' weirs, 'barbs' etc., are frequently used to mitigate the effect of the bottom and bank scours and also help protect river structures against undermining failure.

Local scours have their maxima near banks and hydraulic structures and especially in the regions of the sharp river bends (at meander angles $>90$ degrees and relative radius of curvature $2.0<\mathrm{R} / \mathrm{B}<3.0$ ). Inspection of various river structures in the Carpathian region of the Ukraine showed that, under similar hydraulic conditions, the destructive effect of scouring in the vicinity of these structures substantially exceeded that observed in the vicinity of concave river banks

\subsection{Objectives}

The main goal of our ongoing research is to determine the relationships between flow structure kinematics and scour intensity. A second objective is to investigate the movement of bed sediments as it relates to flow control structures and deployment of flow internal energy. Two methods, which account for turbulence levels, sediment transport and other factors to calculate channel bed deformations, are applied in the study.

\subsection{Local scour classification}

The following classification of local scouring was developed to assist in choosing the appropriate scour estimation method.

- location of scour

- concentrated scour (due to vortex)

- distributed lengthwise

- distributed over area

- origin

- $\quad$ interaction of parallel or near-parallel streams

- highly turbulent flow

- mostly caused by vortex

- $\quad$ soil type

- relatively shallow, homogenous

- non-coherent, non-homogenous

- non-homogenous that yields armoring

- content of transit sedimentation

- absence of sediment transport 
- constant rate of sediment transport

- random sediment transport

- large rises in river bed that affect flow structure and rate of scouring.

\subsection{Background}

It is a well-accepted fact that similarity exists between the geometrical features of scour holes, the flow structure, and the nature of the physical processes involved. Thus, scour holes formed by vortices generated behind partiallysubmerged river-bed features having slanted ridges, behind spurs and slanted backward-facing bottom steps (Figure 1, (a) and (b)) are similar to those forming behind the ridges produced by scour holes. In Figure 1 (a) the lateral obstacle, having width $\mathrm{y}_{1}$, intensifies current at the 3 -D separation zone.

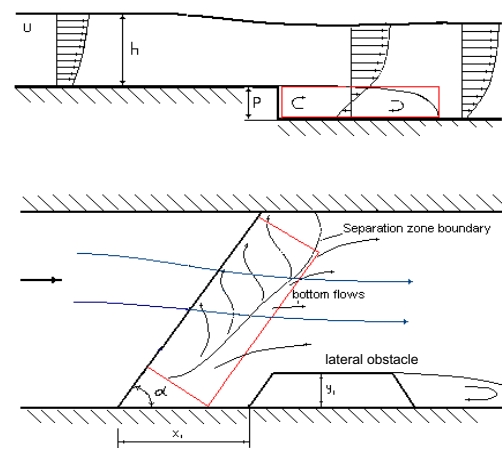

(plan view)

(a)

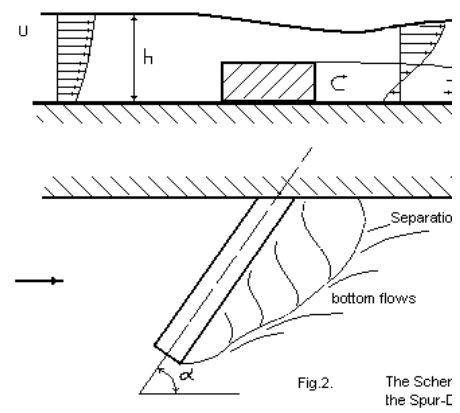

(plan view)

(b)

Figure 1: Flow structures behind two types of channel bed feature: (a) backward-facing step, and (b) spur dyke.

The geometrical form of scour holes, near bridge piers or abutments or near the head of a spur dyke, is reflected in the formation of analogous kinematic flow structures. Laboratory experiments were performed to determine related maximum local scour and turbulence intensity. The severity of local scouring associated with different channel bend angles and sediment transport rates were investigated along with the governing kinematic structures [1].

\section{Scheme of river-bed regulation}

Various river bed scour profiles occurring in nature require some form of control. One example is transformation of the bed form of a mountain river into that of a plane river at the 'foot-hills' zone. This zone is particularly vulnerable to the frequently changing direction of the river current, due to massive sediment 
transport and subsequent partial deposition along the plain zone during flood flows. The deposited sediments create shallows with multiple islands that can transform a single river channel into multiple (braided) streams. Furthermore, these new deposits can cause unpredictability in steam direction, which may change with each flood event. Excessive sedimentation can also elevate a river bed relative to the adjacent lands, thereby increasing the likelihood of major flooding. In mountainous regions of the Ukraine, where channel instability of the type describe above is common, novel forms of river control structure have recently been introduced to help maintain stable, single, and well-defined watercourses.

One such device is a low-profile (submerged) spur-like structure, installed at an angle to the cross-stream direction (Figure 2). This device has two main effects: it deepens the channel in the central region while at the same time concentrating the sediment bed-load towards a stable bank region. Another successful application of this particular device is its use on tight river bends to reduce the severity of local scouring next to unstable regions of the outside channel bank. In Figure 2 the protective dam (1) and the upper portions of the spur-dykes (2) are built utilizing local sandy-gravel materials. The submerged parts of the dykes (3), which are inclined upstream to the main flow direction, are made of stronger materials like concrete, reinforced concrete or stone gabions. With time, these devices encourage local sediment deposition in the intervening spaces between the spur dykes. This, in turn, leads to improved stability of the channel bank regions. Depending on the type of application, various designs for portion (3) of the device have been developed. In Figure 2 surface currents of the flow are represented by continuous lines; the near-bottom currents are shown as dotted lines.

Figure 3 shows a successful application of upstream-pointing spurs to protect the outside-bank region of a river bend in the Carpathians region of the Ukraine. The process of progressive in-filling of the spaces between the spurs with graveltype sediments helps to stabilize and protect the outer bank from erosion. This stream-bank protection method has been shown to be not only hydraulically effective but also cost effective in sub-mountain foothill zones if longitudinal dams that constrain the flow are also employed on the unstable reaches of river channels.

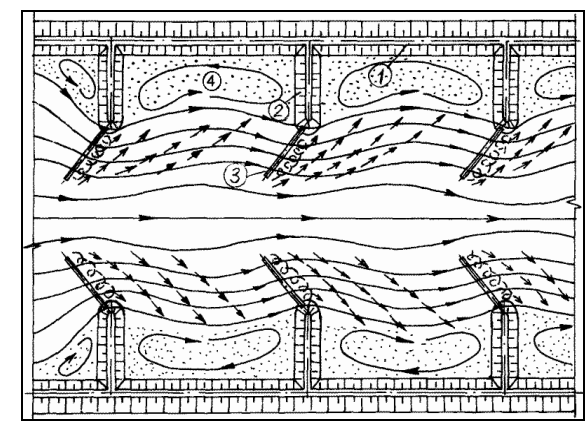

Figure 2: $\quad$ Example of a river bed scour regulation device. 


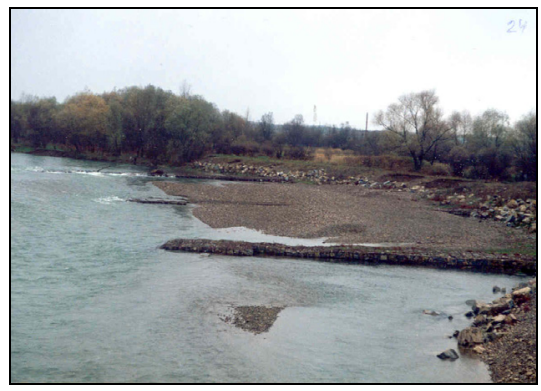

Figure 3: Upstream-pointing spur dykes promote sedimentation in the inbetween regions.

\section{Modelling considerations}

Two mathematical models were used to forecast the channel bottom profiles that develop following installation of the different river structures. One case assumes the channel bed to be comprised of a relatively homogeneous mix of small sand particles. The other assumes the bed to be comprised of non-homogeneous materials. The first model utilises diffusion theory and is based on the assumption that only two major processes determine the deformation intensity rate: the diffusion of rigid particles and their convection [2]. The second model accounts for critical conditions with regards to stability of a single particle. Because of the limited space here a complete description of the two models is not possible. Detailed descriptions of the two models and their respective development are presented elsewhere [3].

Applications of the models provided a description of the channel bottom development processes with time. The approximate kinematics structure obtained with the 2-D analytical approach, when combined with ideal flow theory, provided a good approximation of the resulting channel bottom deformations.
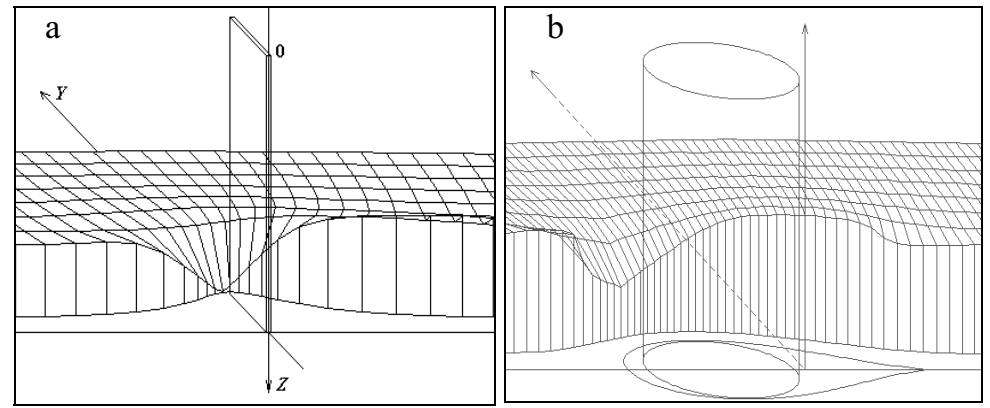

Figure 4: Computer-generated bed profiles associated with: (a) a spur-dyke type structure, and (b) cylindrical bridge pier. 
Figure 4 is an example of the patterns of channel-bed erosion and deposition that were generated in the vicinity of hypothetical spur-dyke and cylindrical pier structures using the 'diffusion theory' model. The mathematical model based on the 'single particle' concept was developed to describe the movement of nonhomogeneous, primarily large sediment particles. This approach is especially well suited when considering mountain river flows.

Spur dikes are important elements in river management practice. They are used to not only protect river banks from erosion during flood flows but also enhance recirculation of water between spurs during low flows. Spur dike applications have also proven to be a significant benefit to the overall ecology of rivers [4-6].

Important hydraulic parameters in spur design are: water depth; angle of flow attack, and stream velocity. The following spur parameters are considered the principal ones in terms of characterizing the flow pattern near the structure.

- The upstream angle of the spur-dyke $\alpha$, relative to the tangent line to the bank at the spur location. Typically this angle should range between $45^{\circ}$ to $60^{\circ}$.

- The spur height $\mathrm{p}$. The spur must generate secondary currents of sufficient intensity, but at the same time not to be an obstacle of extreme hydraulic resistance. Also, it should not become an obstacle to ice passage. In general, $\mathrm{p}$ should be in the range $0.25<\mathrm{p} / \mathrm{H}<0.33$, where $\mathrm{H}$ is the average flow depth at the channel forming discharge.

- The distance between successive spurs in a system must be between 1.5 and $2.5 \mathrm{~L}$, where $\mathrm{L}$ is the spur's length projection on the normal to the bank-line.

- Spur width depends on the construction technology used.

\section{Conclusions}

The analysis of both field and experimental data relating to local scouring phenomena observed in the beds of river reaches located in 'foot-hills' regions of the Ukraine indicated that maximum scouring is dependent on both sediment type and the inner structure of the river flow. The two methods proposed to calculate bed deformations account for high turbulence levels, sediment transportation and other factors.

The analytical procedures developed in this study to estimate maximum scour depths were validated through experiment performed in laboratory channels. The prime cause of maximum scouring were the active concentrated bottom vortices generated in the flow fields

The systems of longitudinal dams and spur-dykes investigated in this study to reduce the severity of river bed and bank scouring proved to be a highly effective erosion -protection measure for all cases considered. 


\section{References}

[1] Schodro A. E. Physical bases of local scour accounts near river hydraulic engineering structures // Hydraulics and Hydraulic Engineering. Republic. Interdepartmental. Scientific Collection.- Kiev: Tehnika, 1997. - Issue 59 (in Russian)

[2] Bomba A. Ya., Schodro A. E., Baranovsky S.V. Modelling and research of singularly-perturbated diffusion processes in contrast environments // Volin Mathematical Bulletin - Rivne: Issue. 2, 1996, PP.25-27 (in Ukrainian)

[3] Schodro A. E. Mathematical modeling of the single bottom particle stability. // Highways and road-building. Scientific Collection of the National Transport University, Kiev 2004. Issue 71., pp.206-215.

[4] Kirienko I.I, Schodro A.E., Shuminskiy V.D., Shinkaruk L.A. The Recommendations on Submerged Spur-Dykes Design on Carpathian Rivers - Exactly: Minvodhoz USSR, UIIVH, 1986.- 62 p. (in Russian)

[5] Kirienko I.I, Shuminskiy V.D., Shinkaruk L.A. The Recommendations on Regulation Structures Design on Carpathian Rivers, Minvodhoz USSR, UIIVH, 1991.- 149p (in Russian).

[6] Unger J., Hager W. H. and Shchodro A. E., Basic flow pattern in spur dykes. 29-th Convegno di idraulica e costrusioni idrauliche. - Trento, 710 September. - Edit. Bios. - Vol. 1, Tema A, pp. 1147-1154. 2004. 